\title{
Mitral repair claims victory over replacement at the time of aortic valve operation
}

\author{
Vinay Badhwar, MD, ${ }^{a}$ and Jeffrey P. Jacobs, $\mathrm{MD}^{\mathrm{b}}$
}

See related article on pages 1614-9.

In this issue of the Journal, Kilic and colleagues ${ }^{1}$ elegantly examine the claims-based National Inpatient Sample (NIS) database to showcase the potential merits of performing mitral valve (MV) repair instead of MV replacement at the time of aortic valve replacement (AVR). From an estimated 41,417 patients, they reveal an unadjusted mortality benefit with MV repair (7.9\%) compared with MV replacement $(10.1 \%)$ with an adjusted odds ratio of $0.63(95 \%$ confidence interval, 0.51-0.77), but no difference in major morbidity.

In addition to well-known preoperative comorbidities, the outcomes of patients following MV surgery with AVR are influenced by several specific clinical factors, including mitral pathoetiology. Patients with degenerative MV disease clearly fare much better with repair at the time of AVR. ${ }^{2-4}$ However, for those presenting with rheumatic mitral disease at the time of AVR, the early and late mortality benefit of MV repair is lost and reoperation rates are higher, suggesting that these patients may be best served with MV replacement. ${ }^{2,3}$ Analyses with robust clinical data from national registries enable the granular assessment of important clinical factors that may better aid clinical decision making. When the focus was placed on a pure mitral regurgitation etiology in 23,404 patients undergoing mitral surgery with AVR, ${ }^{4}$ not only was mortality better with MV repair over MV replacement (odds ratio, $0.61 ; 95 \% \mathrm{CI}, 0.55-0.68 ; P<.0001)$, but there was also a marked benefit in major morbidity.

Clearly, the analysis by Kilic and colleagues ${ }^{1}$ draws important conclusions. However, the generalizability of these findings is subject to the inherent limitations of the NIS database. The NIS is a claims-based stratified probability sample of $20 \%$ of the hospital admissions in the

From the Department of Cardiothoracic Surgery, ${ }^{a}$ University of Pittsburgh, Pittsburgh, Pa; and the Division of Cardiothoracic Surgery, ${ }^{\mathrm{b}}$ All Children's Hospital, St Petersburg, Fla.

Disclosures: Authors have nothing to disclose with regard to commercial support.

Received for publication March 4, 2015; accepted for publication March 7, 2015; available ahead of print April 9, 2015

Address for reprints: Vinay Badhwar, MD, Department of Cardiothoracic Surgery, University of Pittsburgh, 200 Lothrop St, C-724, Pittsburgh, PA 15213 (E-mail: badhwarv@upmc.edu).

J Thorac Cardiovasc Surg 2015;149:1620-1

$0022-5223 / \$ 36.00$

Copyright (c) 2015 by The American Association for Thoracic Surgery

http://dx.doi.org/10.1016/j.jtcvs.2015.03.010
United States. It excludes several US states and individual hospitals and is composed of a random sample of major community and urban hospitals. Due the

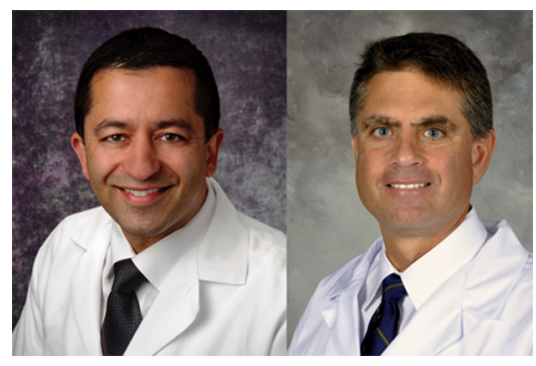
internal sampling design, analysis of NIS data may not always be straightforward if the intention goes beyond reporting the incidence of fixed outcomes of operations performed. Furthermore, the accuracy of type and number of procedures performed and the clinical granularity of results obtained from claims data sources can differ substantially with those from clinical data.

Kilic and colleagues ${ }^{1}$ laudably performed a regression model for mortality on the data available to confirm the substantive influence of heart failure, peripheral or cerebrovascular disease, liver disease, and renal failure. They also reference real-world outcomes, although the NIS represents a $20 \%$ sample of up to 1050 potential sites. During the same 2008 time frame of the study, The adult cardiac surgery component of the Society of Thoracic Surgeons National Database had 962 US participants with a penetrance linked to claims-based Medicare data of $86 \%$ to $90 \%$, and it now has 1084 participants with a penetrance of more than $90 \%{ }^{6}$

Tricuspid valve repair-and especially replacementhas been implicated in higher operative mortality during concomitant operations. ${ }^{7}$ In the study by Kilic and colleagues, ${ }^{1}$ tricuspid replacement occurred more frequently in the MV replacement group and may have influenced the unadjusted mortality results. The NIS data remains unable to adjust for the severity of tricuspid or mitral regurgitation, which are known surrogates of patient complexity. This may further influence outcome interpretation.

The NIS database is quite useful for estimating trends and incidences of disease states and their related hospital costs. However, due to the claims-based nature of the data, granularity of itemized cost breakdown may be lacking. This may be particularly relevant with devicerelated costs. In the complex multivalve procedures studied by Kilic and colleagues, ${ }^{1}$ the prosthesis cost differential between MV repair and MV replacement groups may have influenced the interpretation of NIS total costs. Although interesting and fiscally intuitive, cost may 
therefore not necessarily be a directly proportional surrogate of outcome.

We congratulate Kilic and colleagues ${ }^{1}$ on their important contribution and agree with their findings of improved outcomes with MV repair instead of MV replacement at the time of AVR. Their conclusions based on claims data are congruent with those obtained from clinical data. Whenever indicated and anatomically feasible, performing MV repair is recommended.

\section{References}

1. Kilic A, Grimm JC, Magruder T, Sciortino CM, Whitman GJR, Baumgartner WA, et al. Trends, clinical outcomes, and cost implications of mitral valve repair versus replacement concomitant with aortic valve replacement. J Thorac Cardiovasc Surg. 2015;149:1614-9.

2. Coutinho GF, Correia PM, Antunes MJ. Concomitant aortic and mitral surgery: to replace or repair the mitral valve? J Thorac Cardiovasc Surg. 2014;148:1386-92.
3. Saurav A, Alla VM, Kaushik M, Hunter CC, Mooss AV. Outcomes of mitral valve repair compared with replacement in patients undergoing concomitant aortic valve surgery: a meta-analysis of observational studies. Eur J Cardiothorac Surg. November 5, 2014 [Epub ahead of print].

4. Thourani VH, Suri RM, Rankin JS, He X, O'Brien SM, Badhwar V, et al. Does mitral valve repair offer an advantage over replacement in patients undergoing aortic valve replacement? Ann Thorac Surg. 2014; 98:598-603.

5. Mack MJ, Herbert M, Prince S, Dewey TM, Magee MJ, Edgerton JR. Does reporting of coronary artery bypass grafting from administrative databases accurately reflect actual clinical outcomes? J Thorac Cardiovasc Surg. 2005;129: 1309-17.

6. Jacobs JP, Edwards FH, Shahian DM, Haan CK, Puskas JD, Morales DLS, et al. Successful linking of The Society of Thoracic Surgeons Adult Cardiac Surgery Database to Centers for Medicare and Medicaid Services Medicare data. Ann Thorac Surg. 2010;90:1150-7.

7. Suri RM, Thourani VH, Englum BR, Rankin JS, Badhwar V, Svensson LG, et al. The expanding role of mitral valve repair in triple valve operations: contemporary North American outcomes in 8,021 patients. Ann Thorac Surg. 2014;97: 1513-9. 